University of Wollongong

Research Online

Faculty of Social Sciences - Papers (Archive) Faculty of Arts, Social Sciences \& Humanities

2005

Novel in vitro exposure techniques for toxicity testing and biomonitoring of airborne contaminants

\author{
Shahnaz Bakand \\ University of Wollongong, sbakand@uow.edu.au \\ Chris Winder \\ University of New South Wales \\ Christian Khalil \\ University of New South Wales \\ Amanda Hayes \\ University of New South Wales
}

Follow this and additional works at: https://ro.uow.edu.au/sspapers

Part of the Education Commons, and the Social and Behavioral Sciences Commons

Research Online is the open access institutional repository for the University of Wollongong. For further information contact the UOW Library: research-pubs@uow.edu.au 


\title{
Novel in vitro exposure techniques for toxicity testing and biomonitoring of airborne contaminants
}

\author{
Abstract \\ Poster presented at the 5th World Congress on Alternatives and Animal Use in the Life Sciences, 21-25 \\ August 2005, Berlin, Germany \\ Keywords \\ vitro, techniques, toxicity, testing, airborne, novel, biomonitoring, exposure, contaminants \\ Disciplines \\ Education | Social and Behavioral Sciences

\section{Publication Details} \\ Bakand, S., Winder, C., Khalil, C. \& Hayes, A. (2005). Novel in vitro exposure techniques for toxicity testing \\ and biomonitoring of airborne contaminants. ALTEX : Alternativen zu Tierexperimenten, 22 (Supp. 1), 184.
}




\title{
Relationship between total antioxidant activity of plasma and parameters related to oxidative stress induced by hepatotoxic drugs in rats
}

\author{
Abdolamir Allameh, Abolfazl Dadkhah and Zahra Islamifar \\ Tarbiat Modarres University, Department of Clinical Biochemistry, Faculty of Medical Sciences, Tehran, Iran
}

Introduction: Antioxidant defense system encompasses the enzymatic and non-enzymatic factors some of which are often measured in tissues. Measurement of all these parameters is not feasible. Total Antioxidant Capacity (TAC) of plasma is a single assay that represents the balance between pro- and antioxidants factors. In this study the reliability of TAC of plasma as an index of oxidative stress was assessed in relation to formation of lipid peroxidation and changes in individual antioxidants.

Methods: Rats were treated with different doses of acetaminophen or menadione, blood was collected and ferric reducing ability of plasma (FRAP) was determined as a measure of TAC. The rate of lipid peroxidation products were measured in plasma. The relationship between FRAP and antioxidants such as blood glutathione, plasma bilirubin, plasma uric acid and total protein together with catalase and superoxide dismutase (SOD) activities in erythrocytes were assessed.
Results: FRAP was markedly increased (5-6 fold) in rats following administration of a single i.p dose of APAP to rats. Elevation of FRAP was observed to be highest, 4-12 h after APAP injection. FRAP was increased depending on APAP dose given. Elevation in FRAP was inversely related to the rate of lipid peroxidation in liver. Interestingly, in growing rats among the enzymatic and non-enzymatic factors measured, plasma bilirubin and erythrocyte's superoxide dismutase (SOD) were correlated with changes in FRAP.

Discussion: FRAP is a simple and reliable assay for assessment of whole body antioxidant capacity. FRAP changes due to hepatotoxins is correlated with certain antioxidant factors namely bilirubin and SOD.

\section{Poster}

\section{Novel in vitro exposure techniques for toxicity testing and biomonitoring of airborne contaminants}

\author{
Shahnaz Bakand, Chris Winder, Christian Khalil and Amanda Hayes \\ The University of New South Wales, Chemical Safety and Applied Toxicology (CSAT) Laboratories, School of Safety Science, \\ Sydney, Australia
}

Exposure to air toxicants is a major contributor to human health problems. The aim of this study was to develop practical and reproducible in vitro techniques for assessing the toxicity of airborne contaminants. Two methods were developed based on the physiochemical properties of test chemicals: static and dynamic direct exposure techniques at the air/liquid interface. Xylene, Toluene and Nitrogen dioxide were chosen as a model test compounds. Human cells including A549 (lung derived), HepG2 (liver derived) and skin fibroblasts were grown in porous membranes. For the static method, test atmospheres of volatile organic solvents were generated in glass chambers $(322 \mathrm{ml})$ and cells were exposed to airborne concentrations for 1 hour at $37^{\circ} \mathrm{C}$. For the dynamic method, cells on membranes were placed in horizontal diffusion chambers and exposed to dynamic flow
$(25 \mathrm{ml} / \mathrm{m})$ of test gas for 1 hour at $37^{\circ} \mathrm{C}$. Cytotoxicity was investigated using the MTS (tetrazolium salt; Promega), NRU (neutral red uptake; Sigma) and ATP (adenosine three phosphate, Promega) assays. Xylene (e.g. $\mathrm{IC}_{50}=5,350 \pm 328 \mathrm{ppm}$, NRU; $\mathrm{IC}_{50}=5,750 \pm 433 \mathrm{ppm}$, MTS in fibroblasts) was found to be more toxic than Toluene (e.g. $\mathrm{IC}_{50}=10,500 \pm 527 \mathrm{ppm}$, NRU; $\mathrm{IC}_{50}=11,200 \pm 1044$ ppm, MTS in fibroblasts) in all cells tested. Dose dependant effects of $\mathrm{NO}_{2}$ were observed in human cells tested. Our findings suggest that the static direct exposure is a practical technique for assessing the toxicity of volatile compounds. Further, dynamic direct exposure offers the potential for respiratory toxicity studies and as an advanced technology for biomonitoring of airborne contaminants. 